\title{
Actividad antibacteriana in vitro de Curcuma longa (Zingiberaceae) frente a bacterias nosocomiales en Montería, Colombia
}

\author{
Nelson Méndez Álvarez, Alberto Angulo Ortíz \& Orfa Contreras Martínez* \\ Grupo de Química de los Productos Naturales, Universidad de Córdoba, Cra. 6 № 76-103 Montería, Colombia; \\ nemendez15@gmail.com, aaangulo@correo.unicordoba.edu.co,*oicontreras@correo.unicordoba.edu.co
}

\author{
Recibido 21-VIII-2015. Corregido 07-III-2016. Aceptado 04-IV-2016.
}

\begin{abstract}
In vitro antibacterial activity of Curcuma longa (Zingiberaceae) against nosocomial bacteria in Montería, Colombia. Bacterial resistance is a growing health problem worldwide that has serious economic and social impacts, compromising public health, and the therapeutic action of current antibiotics. Therefore, the search for new compounds with antimicrobial properties is relevant in modern studies, particularly against bacteria of clinical interest. In the present study, in vitro antibacterial activity of the ethanol extract and essential oil of Curcuma longa (Zingiberaceae) was evaluated against nosocomial bacteria, using the microdilution method. Escherichia coli strains, Pseudomonas aeruginosa, Klebsiella pneumoniae, Proteus sp. were used, Salmonella sp. and Bacillus sp., isolated from nosocomial infections in a hospital in the city of Monteria and reference strains of $S$. aureus ATCC 43300, S. aureus ATCC 29213, S. aureus ATCC 25923, P. aeruginosa ATCC 27853, E. coli ATCC 25922 and K. pneumonia ATCC 700603. The ethanol extract antibacterial profile was more efficient at higher concentrations (1 $000 \mathrm{ppm}$ ), obtaining significant percentages of reduction of more than $50 \%$ against $K$. pneumoniae ATCC 700603 and a clinical isolate of E. coli; while compared to Bacillus clinical isolate, was more active than the essential oil. For the rest of microorganisms, the reduction percentages obtained at a concentration of $1000 \mathrm{ppm}$ varied between 17 and $42 \%$ with ethanolic extract, and 8 to $43 \%$ with essential oil. At concentrations of 100 and $500 \mathrm{ppm}$ antibacterial activity of the extracts was lower. The results indicated that the ethanolic extract and essential oil of $C$. longa rhizomes have active compounds with antibacterial properties that could be used in future research as a therapeutic alternative for the treatment of infections caused by nosocomial pathogens. Rev. Biol. Trop. 64 (3): 1201-1208. Epub 2016 September 01.
\end{abstract}

Key words: Curcuma longa, antibacterial activity, Zingiberaceae, essential oil, microdilution.

Uno de los grandes retos a los que se enfrentan las unidades de salud a nivel mundial, tiene que ver con el tratamiento y control de infecciones nosocomiales producidas por bacterias con resistencia o multiresistencia antibiótica. Este creciente problema de salud pública, tiene gran importancia en la actualidad, por las implicaciones económicas, sociales y humanas que causa. Además, genera una complicación importante en el cuidado hospitalario del paciente, que aumenta el índice de morbilidad y mortalidad, el tiempo de hospitalización y los costos asociados, el personal sanitario y el desgaste de los sistemas de salud (Barahona et al., 2014; Álvarez et al., 2014;
Khan, Ahmad, \& Mehboob, 2015). Ante esta situación, es conveniente fomentar la búsqueda de nuevos medicamentos a partir de fuentes naturales, ya que las perspectivas futuras en el uso de las drogas antibióticas de hoy son todavía inciertas. Por ello, la identificación y evaluación de moléculas con actividad biológica, aisladas de fuentes naturales, es cada vez más relevante en los estudios modernos a nivel mundial (Negi, 2012). La búsqueda de nuevos compuestos con actividad antibacteriana, dentro de la medicina herbolaria tradicional, representa un factor determinante para el tratamiento de las infecciones producidas por microorganismos. Sin embargo, es necesario 
categorizar este tipo de estudios, porque la actividad antimicrobiana de extractos vegetales puede diferir entre cepas de una misma especie. Adicionalmente, sus propiedades pueden variar en función de los órganos vegetales empleados, los métodos de extracción y pueden cambiar en función de las estaciones o periodos de recolecta y las diferentes condiciones fisicoquímicas del terreno (Martínez, Betancourt, Alonso, \& Jauregui, 1996; Jain, Bansal, \& Bhasin, 2009).

En general, las plantas y sus constituyentes ocupan una posición importante en el conocimiento de nuevas sustancias y principios activos (Gurib, 2006). En el mundo, se han desarrollado numerosas investigaciones enfocadas a la búsqueda de nuevos compuestos con propiedades antimicrobianas (Saha \& Paul, 2014; Baharudin, Hamid, \& Susanti, 2015). Curcuma longa L. (Zingiberaceae) se ha utilizado desde la antigüedad como condimento, colorante y estimulante aromático (Chairman, Jayamala, Christy, \& Singh, 2015), y se le han atribuido propiedades antifúngicas (Al-Daihan et al., 2013), antibacterianas (Rawat \& Rawat, 2015), antiparasitarias (Singh, Mehta, Mehta, \& Shukla, 2011), antivirales (Kim et al., 2009), antioxidantes, antiinflamatorias (Ramadan, AlKahtani, \& El-Sayed, 2011) y anticancerígenas (Annapurna, Suhasin, Raju, Jaya, \& Siva, 2011). Si bien C. longa ha sido ampliamente estudiada por sus propiedades antibacterianas (Rao \& Mittal, 2014; Gaikwad, Bodhankar, Ittadwar, \& Waikar, 2014; Chairman et al., 2015), ha sido pobremente caracterizada en el contexto regional (Falco, Martínez, Rodríguez, Núñez, \& Sevillano, 2011; García, Olaya, Sierra, \& Padilla 2011; Coy \& Acosta 2013), y en especial, frente a bacterias intrahospitalarias. Por ello, en la presente investigación se evaluó la actividad antibacteriana in vitro del extracto etanólico y del aceite esencial de C. longa, frente a bacterias nosocomiales.

\section{MATERIALES Y MÉTODOS}

Material vegetal: Los rizomas de $C$. longa fueron donados por la Secretaría Técnica de Plantas Medicinales, Aromáticas,
Condimentarias y Afines, de sus cultivos ubicados en el municipio de Canalete ( $8^{\circ} 47^{\prime} 24^{\prime \prime}$ $\mathrm{N}-76^{\circ} 14^{\prime} 28^{\prime \prime} \mathrm{W}$, altitud $50 \mathrm{msnm}, 28^{\circ} \mathrm{C}$ ), Departamento de Córdoba, Colombia, en febrero 2013 durante la estación seca. La confirmación taxonómica fue realizada en el Herbario de la Universidad de Córdoba, donde reposa una muestra (HUC-003112).

Obtención del extracto crudo: Los rizomas se lavaron con agua destilada estéril; seguidamente, fueron cortados en rodajas de 2-4 $\mathrm{mm}$ de espesor y se secaron durante ocho horas a temperatura ambiente. Posteriormente, fueron pulverizados $300 \mathrm{~g}$ y sometidos a percolación por 48 horas con $1.5 \mathrm{~L}$ de etanol al $96 \%$. El disolvente se concentró al vacío a 45 ${ }^{\circ} \mathrm{C}$ en un rotaevaporador (BÜCHI Rotavapor R-200) hasta obtener el extracto crudo. A este extracto se le realizó una marcha fitoquímica preliminar, que es una prueba para determinar de manera cualitativa la presencia o ausencia de alcaloides, flavonoides, taninos, esteroides, antraquinonas y saponinas, siguiendo la metodología descrita en Sanabria (1983).

Obtención del aceite esencial: A partir de $500 \mathrm{~g}$ de rizoma, previamente cortados en rodajas y secados al sol durante dos horas, se obtuvieron $2.8 \mathrm{~mL}$ de aceite esencial, mediante destilación por arrastre con vapor de agua en un equipo tipo Clevenger. El aceite obtenido se secó con $\mathrm{Na}_{2} \mathrm{SO}_{4}$ anhidro y se almacenó a $4{ }^{\circ} \mathrm{C}$ protegido de la luz.

Microorganismos usados: Se emplearon cepas de Escherichia coli, Pseudomonas aeruginosa, Klebsiella pneumoniae, Proteus sp., Salmonella sp. y Bacillus sp., aisladas a partir de infecciones nosocomiales en el Hospital San Jerónimo de Montería y cepas de referencia $S$. aureus ATCC 43300, S. aureus ATCC 29213, $S$. aureus ATCC 25923, P. aeruginosa ATCC 27853, E. coli ATCC 25922 y K. pneumoniae ATCC 700603. Los cultivos bacterianos se crioconservaron a una temperatura de $-20{ }^{\circ} \mathrm{C}$ en medio BHI (infusión cerebro corazón) que contenía $30 \%(\mathrm{v} / \mathrm{v})$ de glicerol y $0.6 \%$ de 
agar. Las cepas de trabajo fueron mantenidas por subcultivos periódicos preservados a $4{ }^{\circ} \mathrm{C}$. Para todo el estudio se siguió la normatividad ética establecida por el Ministerio de Salud de Colombia, en su resolución N008430 de 1993.

Preparación y estandarización del inóculo bacteriano: Partiendo de un cultivo axénico, se tomaron de 3 a 5 colonias y se sembraron en $9 \mathrm{~mL}$ de caldo BHI (Merck), e incubadas a $36 \pm 1{ }^{\circ} \mathrm{C}$ durante $16-18$ horas. Tras la incubación, se realizaron diluciones seriadas de la suspensión bacteriana, midiendo la densidad óptica de cada dilución a $630 \mathrm{~nm}$ en un espectrofotómetro (GENESYS ${ }^{\mathrm{TM}}$ 20, Thermo Spectronic), hasta alcanzar una absorbancia comprendida entre 0.08 y 0.13 (Valgas, Souza, Smânia, \& Smânia, 2007). Esta absorbancia correspondió a $2 \times 10^{8} \mathrm{UFC} / \mathrm{mL}$, y a una turbidez 0.5 en la escala de MacFarland (CLSI, 2009; Alves, Guzman, Figueroa, Tello, \& De Olivera 2011).

Actividad antibacteriana: Para los ensayos de actividad antibacteriana, el extracto etanólico y el aceite esencial, se diluyeron en dimetilsulfóxido DMSO al $10 \%$ y Tween- 80 al $5 \%$, respectivamente, a una concentración inicial de 2000 ppm (Matasyoh, Kiplimo, Karubiu, \& Hailstorks, 2007; Valgas et al., 2007). Las concentraciones a ensayar (100, 500 y $1000 \mathrm{ppm}$ ), se obtuvieron por adición de caldo BHI (Valgas et al., 2007). La actividad antibacteriana se evaluó por el método de microdilución, siguiendo la metodología implementada por Valgas et al. (2007), y teniendo en cuenta las recomendaciones del Clinical and Laboratory Standards Institute - CLSI sobre la preparación y estandarización del inóculo bacteriano, que se ajustó como se describió previamente. Luego, $100 \mu \mathrm{L}$ de las diferentes concentraciones del extracto etanólico y el aceite esencial, fueron distribuidas en una microplaca de 96 pozos. Cada pozo de prueba fue inoculado con $10 \mu \mathrm{L}$ de la suspensión bacteriana. Como control de esterilidad se utilizaron pozos que contenían el extracto, pero que no fueron inoculados con el microorganismo, y como control de crecimiento, se utilizaron pozos con BHI sin el extracto, pero inoculados con el microorganismo. Los controles positivos fueron antibióticos comerciales (vancomicina, ciprofloxacina y cloranfenicol), mientras que los negativos fueron DMSO al $10 \%$ y Tween80 al $5 \%$. La bandeja de microdilución se incubó a $36 \pm 1{ }^{\circ} \mathrm{C}$ por 24 horas. Tras la incubación, el crecimiento bacteriano se detectó por medición de la densidad óptica a $630 \mathrm{~nm}$ en un lector de ELISA (ChroMate ${ }^{\circledR} 4300$ ). Para evaluar la viabilidad celular, se adicionaron $20 \mu \mathrm{L}$ de una solución alcohólica $(0.5 \mathrm{mg} /$ $\mathrm{mL})$ de bromuro de 3-(4,5-dimetil-2-tiazolil)2,5-difeniltetrazolium (MTT). Todos los ensayos fueron realizados por triplicado.

Se utilizó un diseño experimental completo aleatorizado, en el que se utilizaron tres réplicas para cada uno de los tratamientos anteriormente mencionados (concentraciones del extracto y controles). Con las absorbancias obtenidas se construyeron tablas en el programa Microsoft Excel ${ }^{\circledR}$, expresando los resultados como medias \pm desviaciones estándar. El efecto de las concentraciones de los extractos sobre el crecimiento de los microorganismos se determinó con el porcentaje de reducción del crecimiento bacteriano propuesto por (Sandasi, Leonard, \& Viljoen, 2010) y ajustado por los autores, de la siguiente forma:

$$
\% \mathrm{RC}=[(\mathrm{CC}-\mathrm{CE})-(\mathrm{ATC}-\mathrm{CE})]^{*} 100 /(\mathrm{CC}-\mathrm{CE})
$$

Dónde: \% RC es el porcentaje de reducción del crecimiento bacteriano; $\mathrm{CC}$ es la absorbancia obtenida para el control de crecimiento; CE es la absorbancia obtenida para el control de esterilidad; y ATC es la absorbancia obtenida para una determinada concentración del extracto, CC-CE expresa el crecimiento real de la bacteria, y ATC-CE el crecimiento real de la bacteria a una determinada concentración del extracto.

\section{RESULTADOS}

Los resultados de la actividad antibacteriana del extracto etanólico y del aceite esencial de los rizomas de C. longa se resumen en el 
cuadro 1. De forma general, se observa que a medida que aumenta la concentración del extracto etanólico y del aceite esencial, se produce una disminución en las absorbancias, reflejando una reducción en el crecimiento bacteriano (medido este como porcentaje de reducción de crecimiento, como fue descrito previamente). A todas las concentraciones evaluadas, el extracto etanólico mostró porcentajes de reducción de más del $50 \%$ frente al crecimiento de la cepa $K$. pneumoniae ATCC 700603 [Kp ATCC 700603], y un aislado clínico de E. coli [Ec (AI)], siendo esta reducción evidente, a medida que aumentaba la concentración del extracto. Este comportamiento fue observado también contra las cepas $S$. aureus ATCC 25923 [Sa ATCC 25923], P. aeruginosa ATCC 27853 [Pa ATCC 27853] y aislados clínicos de $P$. aeruginosa $[\mathrm{Pa}(\mathrm{AI})]$ y $K$. pneumoniae [Kp (AI)] (Fig. 1), pero con porcentajes de reducción inferiores al $50 \%$.

La actividad antibacterial del aceite esencial fue menor que el observado con el extracto etanólico, y solo a concentración de 1000 ppm mostró un porcentaje de reducción del crecimiento, superior al $50 \%$ contra un aislado clínico del género Bacillus [B (AI)]. A esta concentración se obtuvieron los mayores porcentajes de reducción contra el resto de los microorganismos usados, destacando porcentajes de $43,43,39$ y $33 \%$ frente a $S$. aureus ATCC 25923 [Sa ATCC 25923], K. pneumoniae [Kp (AI) y Kp (AII)] y S. aureus ATCC 43300 [Sa ATCC 43300], respectivamente. Con el resto de bacterias se obtuvieron porcentajes inferiores (Fig. 2).

CUADRO 1

Absorbancias obtenidas por el método de microdilución

TABLE 1

Absorbance obtained by microdilution method

\begin{tabular}{|c|c|c|c|c|c|c|}
\hline \multirow{2}{*}{ Bacterias } & \multirow{2}{*}{ Código } & \multicolumn{5}{|c|}{ Extracto etanólico } \\
\hline & & C. crec. & $100 \mathrm{ppm}$ & $500 \mathrm{ppm}$ & 1000 ppm & C. est. \\
\hline E. coli & $\mathrm{Ec}(\mathrm{AI})$ & $0.675 \pm 0.069$ & $0.453 \pm 0.011$ & $0.442 \pm 0.005$ & $0.422 \pm 0.021$ & $0.252 \pm 0.012$ \\
\hline K. pneumoniae ATCC 700603 & Kp ATCC 700603 & $0.668 \pm 0.030$ & $0.438 \pm 0.010$ & $0.419 \pm 0.020$ & $0.416 \pm 0.008$ & $0.264 \pm 0.007$ \\
\hline P. aeruginosa ATCC 27853 & Pa ATCC 27853 & $0.603 \pm 0.023$ & $0.589 \pm 0.059$ & $0.587 \pm 0.045$ & $0.545 \pm 0.050$ & $0.252 \pm 0.014$ \\
\hline P. aeruginosa & $\mathrm{Pa}(\mathrm{AI})$ & $0.559 \pm 0.021$ & $0.555 \pm 0.013$ & $0.548 \pm 0.029$ & $0.498 \pm 0.029$ & $0.300 \pm 0.035$ \\
\hline S. aureus ATCC 25923 & Sa ATCC 25923 & $0.518 \pm 0.006$ & $0.484 \pm 0.052$ & $0.456 \pm 0.019$ & $0.405 \pm 0.021$ & $0.252 \pm 0.007$ \\
\hline \multirow[t]{2}{*}{ K. pneumoniae } & $\mathrm{Kp}(\mathrm{AI})$ & $0.571 \pm 0.040$ & $0.471 \pm 0.014$ & $0.457 \pm 0.001$ & $0.451 \pm 0.005$ & $0.276 \pm 0.009$ \\
\hline & & \multicolumn{5}{|c|}{ Aceite esencial } \\
\hline S. aureus ATCC 43300 & Sa ATCC 43300 & $0.659 \pm 0.062$ & $0.556 \pm 0.027$ & $0.553 \pm 0.007$ & $0.517 \pm 0.006$ & $0.233 \pm 0.004$ \\
\hline S. aureus ATCC 25923 & Sa ATCC 25923 & $0.879 \pm 0.078$ & $0.656 \pm 0.046$ & $0.630 \pm 0.025$ & $0.618 \pm 0.030$ & $0.269 \pm 0.008$ \\
\hline S. aureus ATCC 29213 & Sa ATCC 29213 & $0.692 \pm 0.052$ & $0.674 \pm 0.086$ & $0.625 \pm 0.030$ & $0.591 \pm 0.058$ & $0.334 \pm 0.089$ \\
\hline E. coli ATCC 25922 & Ec ATCC 25922 & $0.867 \pm 0.029$ & $0.848 \pm 0.013$ & $0.787 \pm 0.033$ & $0.737 \pm 0.010$ & $0.252 \pm 0.009$ \\
\hline E. coli & Ec (AII) & $1.095 \pm 0.025$ & $1.103 \pm 0.007$ & $1.019 \pm 0.020$ & $0.909 \pm 0.098$ & $0.254 \pm 0.005$ \\
\hline E. coli & $\mathrm{Ec}(\mathrm{AI})$ & $0.675 \pm 0.069$ & $0.654 \pm 0.016$ & $0.649 \pm 0.051$ & $0.597 \pm 0.017$ & $0.252 \pm 0.009$ \\
\hline Proteus sp. & Proteus (AI) & $1.028 \pm 0.014$ & $0.923 \pm 0.036$ & $0.875 \pm 0.019$ & $0.817 \pm 0.031$ & $0.269 \pm 0.005$ \\
\hline Bacillus sp. & $\mathrm{B}(\mathrm{AI})$ & $0.818 \pm 0.027$ & $0.637 \pm 0.044$ & $0.582 \pm 0.052$ & $0.504 \pm 0.100$ & $0.252 \pm 0.009$ \\
\hline K. pneumoniae & $\mathrm{Kp}(\mathrm{AI})$ & $0.975 \pm 0.015$ & $0.926 \pm 0.016$ & $0.804 \pm 0.039$ & $0.668 \pm 0.036$ & $0.263 \pm 0.014$ \\
\hline K. pneumoniae & $\mathrm{Kp}(\mathrm{AII})$ & $1.113 \pm 0.011$ & $1.109 \pm 0.027$ & $1.105 \pm 0.039$ & $0.786 \pm 0.125$ & $0.264 \pm 0.005$ \\
\hline Salmonella sp. & $\mathrm{S}(\mathrm{AI})$ & $0.953 \pm 0.036$ & $0.929 \pm 0.021$ & $0.900 \pm 0.045$ & $0.897 \pm 0.014$ & $0.267 \pm 0.009$ \\
\hline P. aeruginosa ATCC 27853 & $\mathrm{~Pa}$ ATCC 27853 & $1.291 \pm 0.150$ & $1.246 \pm 0.067$ & $1.118 \pm 0.141$ & $1.006 \pm 0.056$ & $0.249 \pm 0.002$ \\
\hline
\end{tabular}

C. crec: control de crecimiento, C. est: control de esterilidad. 


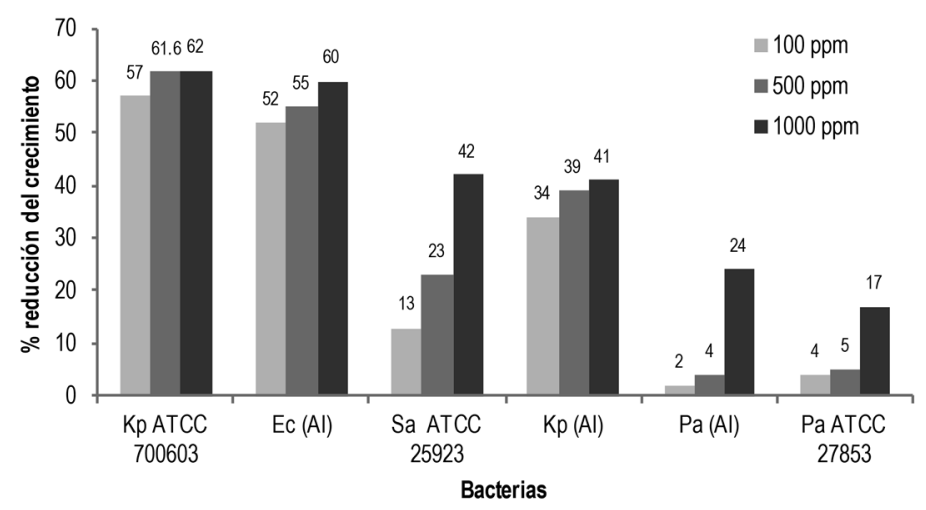

Fig. 1. Porcentajes de reducción del crecimiento bacteriano obtenidos con el extracto etanólico de los rizomas de Curcuma longa.

Fig. 1. Reduction percentages of bacterial growth obtained with the ethanolic extract of Curcuma longa rhizomes.

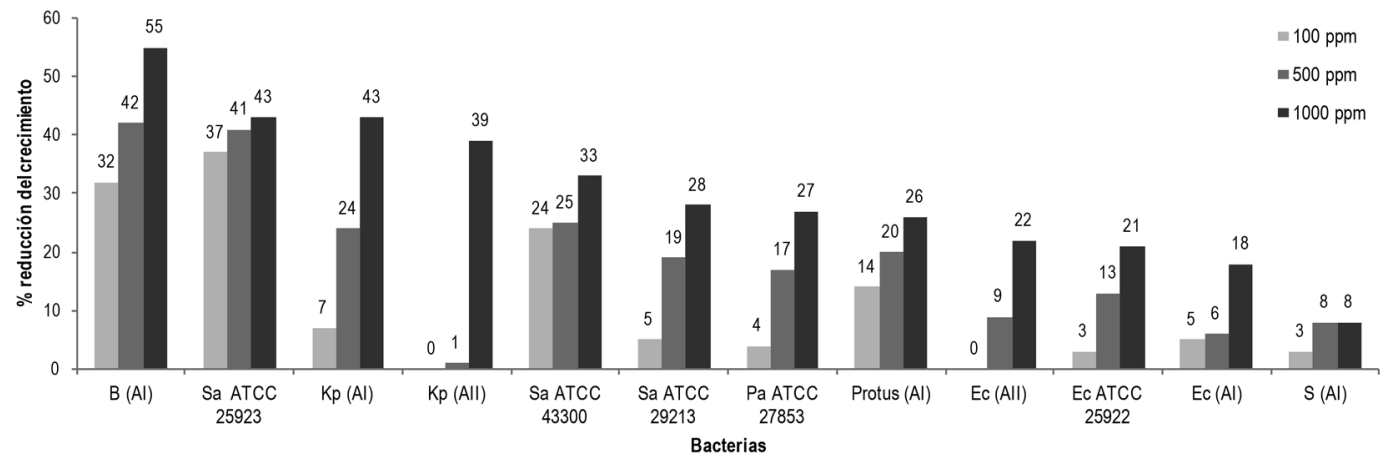

Fig. 2. Porcentajes de reducción del crecimiento bacteriano obtenidos con el aceite esencial de los rizomas de Curcuma longa.

Fig. 2. Reduction percentages of bacterial growth obtained with the essential oil from the rhizomes of Curcuma longa.

Los ensayos colorimétricos basados en la adición de MTT, reflejaron el crecimiento bacteriano, tras el viraje de color experimentado en cada uno de los pozos de la microplaca, excepto en el control de esterilidad. Se evidenció igualmente la inactividad de los controles negativos frente al crecimiento bacteriano. Es de resaltar que las absorbancias obtenidas en los pozos de prueba se mantuvieron por encima del control de esterilidad y por debajo del control de crecimiento, según lo esperado.

El análisis fitoquímico cualitativo preliminar del extracto etanólico, reveló la presencia de saponinas, taninos, alcaloides y flavonoides.

\section{DISCUSIÓN}

Los resultados obtenidos en este estudio indican que el extracto etanólico y el aceite esencial de los rizomas de C. longa poseen propiedades antibacterianas. El extracto etanólico fue el de mayor potencial contra las bacterias evaluadas, con significativos porcentajes de reducción del crecimiento bacteriano. Hay reportes en la literatura científica que muestra valores de concentración mínima inhibitoria (MIC) y concentración mínima bactericida (MBC) de extractos de cúrcuma contra diferentes cepas bacterianas, que varían en el rango 
de 5 a $55 \mathrm{mg} / \mathrm{mL}$ (Chakraborty, Nath, Saikia, \& Sengupta, 2014); estas son concentraciones superiores a las empleadas en este estudio. Asimismo, otros estudios han demostrado que los extractos hidroetanólicos obtenidos de los rizomas, tienen actividad antifúngica y antibacteriana frente a $S$. aureus ATCC 6538 y E. coli ATCC 25922 (Falco et al., 2011). Por otra parte, el extracto etanólico de las hojas y fracciones de diferente polaridad (hexano, acetato de etilo, butanol y etanol) presentaron actividad antimicrobiana contra S. aureus, E. coli y Aspergillus niger, mientras que los curcuminoides (curcumina, demetoxicurcumina y bisdemetoxicurcumina) tuvieron actividad frente a $S$. aureus y $S$. epidermidis (García et al., 2011). En otro estudio (Coy \& Acosta, 2013) con el aceite esencial de C. longa, se obtuvo los siguientes porcentajes de inhibición de crecimiento de $70,60,10$ y $10 \%$, respectivamente, frente a $S$. aureus ATCC 6538, E. faecalis ATCC 29212, E. coli ATCC 25922 y Salmonella tiphymurium ATCC 14028s, respectivamente. Investigaciones similares resaltan diversas propiedades biológicas en otras especies de cúrcuma, incluyendo la actividad antibacteriana y antifúngica de $C$. xanthorrhiza (Mary et al., 2012), C. cedoaria y C. malabarica (Wilson et al., 2005).

Los resultados obtenidos en este estudio, evidencian el perfil antibacteriano de extractos obtenidos de C. longa. Las propiedades antibacterianas del extracto etanólico y el aceite esencial de esta especie, pueden explicarse por el efecto sinérgico entre los diferentes componentes químicos de los extractos y/o por la presencia de otros componentes que incluso pueden ser activos a bajas concentraciones (Soković, Glamočlija, Marin, Brkić, \& van Griensven, 2010). Los metabolitos activos de las plantas pueden exhibir su efecto antimicrobiano, por la degradación de la pared celular, disrupción de la membrana citoplasmática, salida de componentes celulares, alteraciones en la síntesis de ADN y ARN, en el transporte de electrones y en la absorción de nutrientes, afectando la producción de energía y modificando constituyentes en ácidos grasos y fosfolípidos
(Shan, Cai, Brooks, \& Corke, 2007). Un estudio reciente, revela que $S$. aureus muestra deformidad morfológica, con pérdida parcial de la membrana citoplasmática, al ser tratado con extractos obtenidos de los rizomas de $C$. longa (Gupta, Mahajan, \& Sharma, 2015).

El perfil fitoquímico del extracto etanólico evaluado es consistente con los reportes bibliográficos, destacando la presencia de saponinas, taninos, alcaloides y flavonoides (Chairman et al., 2015), siendo estos últimos responsables de la actividad antibacteriana en varias plantas (Cordell, Quinn, \& Farnsworth, 2001). Los resultados de este trabajo permiten concluir que la $C$. longa que crece en la región de Canalete, Córdoba, es capaz de producir compuestos con potencial antibacteriano frente a patógenos nosocomiales, lo que amerita continuar con la búsqueda de los componentes responsables de esta actividad, que puedan emplearse como alternativa terapéutica para el tratamiento de infecciones causadas por bacterias.

\section{AGRADECIMIENTOS}

Este trabajo fue realizado en el marco del proyecto FCB-11-08, financiado por la División de Investigación de la Universidad de Córdoba. Los autores agradecen a Catalina Tovar, del Grupo de Investigación en Enfermedades Tropicales y Resistencia Bacteriana de la Universidad del Sinú, por la donación de las cepas ATCC.

\section{RESUMEN}

La resistencia bacteriana es un problema de salud creciente a nivel mundial que genera graves impactos económicos y sociales, comprometiendo la acción terapéutica de los antibióticos actuales. Por ello, la búsqueda de nuevos compuestos con propiedades antimicrobianas se hace más relevante en los estudios modernos, en especial frente a bacterias de interés clínico. En el presente estudio se evaluó la actividad antibacteriana in vitro del extracto etanólico y el aceite esencial de Curcuma longa L (Zingiberaceae), contra bacterias nosocomiales utilizando el método de microdilución. Se utilizaron cepas de Escherichia coli, Pseudomonas aeruginosa, Klebsiella pneumoniae, Proteus sp., Salmonella sp. y Bacillus sp., aisladas de infecciones nosocomiales en un centro hospitalario de la ciudad de 
Montería y cepas de referencia de $S$. aureus ATCC 43300, S. aureus ATCC 29213, S. aureus ATCC 25923, P. aeruginosa ATCC 27853, E. coli ATCC 25922 y K. pneumoniae ATCC 700603. El perfil antibacterial del extracto etanólico fue más evidente a las concentraciones más altas (1000 $\mathrm{ppm}$ ), obteniendo porcentajes de reducción significativos de más del $50 \%$ frente a $K$. pneumoniae ATCC 700603 y un aislado clínico de $E$. coli, mientras que, frente al aislado clínico del género Bacillus fue más activo el aceite esencial. Para el resto de los microorganismos los porcentajes de reducción obtenidos a una concentración de 1000 ppm variaron entre 17 y $42 \%$ con el extracto etanólico y entre 8 y $43 \%$ con el aceite esencial. A concentraciones de 100 y 500 ppm la actividad antibacteriana de los extractos fue menor. Los resultados obtenidos indican que el extracto etanólico y el aceite esencial de los rizomas de C. longa poseen compuestos activos con propiedades antibacterianas que podrían emplearse en investigaciones futuras, como una alternativa terapéutica para el tratamiento de infecciones producidas por patógenos nosocomiales.

Palabras clave: Curcuma longa, actividad antibacterial, Zingiberaceae, aceite esencial, microdilución.

\section{REFERENCIAS}

Al-Daihan, S., Al-Faham, M., Al-shawi, N., Almayman, R., Brnawi, A., \& Zargar, S. (2013). Antibacterial activity and phytochemical screening of some medicinal plants commonly used in Saudi Arabia against selected pathogenic microorganisms. Journal of King Saud University - Science, 25(2),115-120.

Álvarez, C., Pérez, A., Rosenthal, V., Quintero, J., Chapeta, E., \& Linares, C. (2014). Surgical site infection rates in 4 cities in Colombia: Findings of the International Nosocomial Infection Control Consortium (INICC). American Journal of Infection Control, 42(10),1089-1092.

Alves, E., Guzman, D., Figueroa, J., Tello, J., \& De Olivera, D. (2011). Caracterización antimicrobiana y fisicoquímica de propóleos de Apis mellifera L. (Hymenoptera: Apidae) de la región andina Colombiana. Acta Biológica Colombiana, 16(1),175-184.

Annapurna, A., Suhasin, G., Raju, B., Jaya, G., \& Siva, Ch. (2011). Anti-cancer activity of Curcuma longa linn.(Turmeric). Journal of Pharmacy Research, 4(4), 1274-1276.

Baharudin, M., Hamid, S., \& Susanti, D. (2015). Chemical Composition and Antibacterial Activity of Essential Oils from Three Aromatic Plants of the Zingiberaceae Family in Malaysia. Journal of Physical Science, 26(1),71-81.

Barahona, N., Rodríguez, M., Rosenthal, V., Olarte, N., Villamil, W., \& Rojas, C. (2014). Impact of the International Nosocomial Infection Control Consortium
(INICC) multidimensional hand hygiene approach in three cities of Colombia. International Journal of Infectious Diseases, 19,67-73.

Chairman, M., Jayamala, M., Christy, V., \& Singh, R. (2015). Phytochemical screening and antimicrobial activity of Curcuma longa natural dye. General Medicine, 3,171.

Chakraborty, B., Nath, A., Saikia, H., \& Sengupta, M. (2014). Bactericidal activity of selected medicinal plants against multidrug resistant bacterial strains from clinical isolates. Asian Pacific Journal of Tropical Medicine, 7(Suppl. 1), S435-S441.

Clinical and Laboratory Standards Institute (CLSI). (2009). Instituto de Estándares Clínicos y de Laboratorio. Métodos para Pruebas de sensibilidad a los antimicrobianos por dilución para bacterias que crecen en condiciones aeróbicas. Estándar aprobado-Octava Edición Documento CLSI M07-A8, 29(2),100.

Cordell, G., Quinn, M., \& Farnsworth, N. (2001). The potential of alkaloids in drug discovery. Phytotherapy Research, 15(3),183-205.

Coy, C., \& Acosta, E. (2013). Actividad antibacteriana y determinación de la composición química de los aceites esenciales de romero (Rosmarinus officinalis), tomillo (Thymus vulgaris) y cúrcuma (Curcuma longa) de Colombia. Revista Cubana de Plantas Medicinales, 18(2),37-46.

Falco, A., Martínez, W., Rodríguez, J., Núñez, M., \& Sevillano, E. (2011).Actividad antimicrobiana de extractos hidroetanólicos de limoncillo (Cymbopogon citratus) y cúrcuma (Curcuma longa). Revista Venezolana de Ciencia y Tecnología de Alimentos, 2(1), 85-93.

Gaikwad, A., Bodhankar, M., Ittadwar, A., \& Waikar, S. (2014). Antibacterial activity of isoflavone extracted from Curcuma longa Linn. Zingeberaceae. Journal of Microbiology, Biotechnology and Food Science, 1(1),6-9.

García, L., Olaya, J., Sierra, J., \& Padilla, L. (2011). Análisis fitoquímico preliminar de las hojas y evaluación de la actividad biológica de sus extractos y de los colorantes obtenidos del rizoma de la cúrcuma (Curcuma longa L.) cultivada en el departamento del Quindío. Revista de Investigaciones Universidad del Quindio, 22(2),67.

Gupta, A., Mahajan, S., \& Sharma, R. (2015). Evaluation of antimicrobial activity of Curcuma longa rhizome extract against Staphylococcus aureus. Biotechnology Reports, 6,51-55.

Gurib, A. (2006). Medicinal plants: traditions of yesterday and drugs of tomorrow. Molecular Aspect of Medicine, 27,1-93. 
Jain, P., Bansal, D., \& Bhasin, P. (2009). Antibacterial activity of aqueous plant extracts against Escherichia coli and Bacillus subtilis. Drug Invention Today, 2(4),220-222.

Khan, H., Ahmad, A., \& Mehboob, R. (2015). Nosocomial infections and their control strategies. Asian Pacific Journal of Tropical Biomedicine, 5(7),509-514.

Kim, H., Yoo, H., Kim, J., Park, C., Choi, M., \& Kim, M. (2009). Antiviral effect of Curcuma longa Linn extract against hepatitis B virus replication. Journal of Ethnopharmacology, 124(2),189-196.

Matasyoh, J., Kiplimo, J., Karubiu, N., \& Hailstorks, T. (2007). Chemical composition and antimicrobial activity of essential oil of Tarchonanthus camphoratus. Food Chemistry, 101(3),1183-1187.

Martínez, M., Betancourt, J., Alonso, N., \& Jauregui, A. (1996). Screening of some Cuban medicinal plants for antimicrobial activity. Journal of Ethnopharmacology, 52(3),171-174.

Mary, H., Susheela, G., Jayasree, S., Nizzy, A., Rajagopal, B., \& Jeeva, S. (2012). Phytochemical characterization and antimicrobial activity of Curcuma xanthorrhiza Roxb. Asian Pacific Journal of Tropical Biomedicine, 2(Suppl. 2), S637-S640.

Negi, P. (2012). Plant extracts for the control of bacterial growth: Efficacy, stability and safety issues for food application. International Journal of Food Microbio$\log y, 156(1), 7-17$.

Ramadan, G., Al-Kahtani, M., \& El-Sayed, W. (2011). Anti-inflammatory and anti-oxidant properties of Curcuma longa (Turmeric) versus Zingiber officinale (Ginger) rhizomes in rat adjuvant-induced arthritis. Inflammation, 34(4), 291-301.

Rao, N., \& Mittal, S. (2014). An in vitro evaluation of the antimicrobial activity of Curcuma longa against selected pathogenic microorganisms. Research Journal of Science and Technology, 6(2),71-74.
Rawat, S., \& Rawat, A. (2015). Antimicrobial activity of Indian spices against pathogenic bacteria. Advances in Applied Science Research, 6(3),185-190.

Saha, D., \& Paul, S. (2014). Antibacterial activity of methanol extract of Alpinia conchigera griff (family: Zingiberaceae). Albanian Journal of Pharmaceutical Sciences, 2(1),1-3.

Sanabria A. (1983). Análisis fitoquímico preliminar, metodología y su aplicación en la evaluación de 40 plantas de la familia Compositae. Bogotá, Colombia: Departamento de Farmacia, Universidad Nacional De Colombia.

Sandasi, M., Leonard, C., \& Viljoen, A. (2010). The in vitro antibiofilm activity of selected culinary herbs and medicinal plants against Listeria monocytogenes. Letters in applied microbiology, 50(1),30-35.

Shan, B., Cai, Y., Brooks, J., \& Corke, H. (2007). The in vitro antibacterial activity of dietary spice and medicinal herb extracts. International Journal of Food Microbiology, 117(1),112-119.

Singh, R., Mehta, A., Mehta, P., \& Shukla, K. (2011). Anthelmintic activity of rhizome extracts of Curcuma longa and Zingiber officinale (Zingiberaceae). International Journal of Pharmacy and Pharmaceutical Sciences, 3, 236-237.

Soković, M., Glamočlija, J., Marin, P., Brkić, D., \& van Griensven, L. (2010). Antibacterial effects of the essential oils of commonly consumed medicinal herbs using an in vitro model. Molecules, 15(11),7532-7546

Valgas, C., Souza, S., Smânia, E., \& Smânia, J. (2007). Screening methods to determine antibacterial activity of natural products. Brazilian Journal of Microbiology, 38(2),369-380.

Wilson, B., Abraham, G., Manju, V., Mathew, M., Vimala, B., \& Sundaresan, S. (2005). Antimicrobial activity of Curcuma zedoaria and Curcuma malabarica tubers. Journal of Ethnopharmacology, 99(1), 147-151. 